\title{
Vertical Accuracy Assessment of Open Access Digital Elevation Models using GPS
}

\author{
Fazilova, D., ${ }^{\text {** }}$ Magdiev, K. ${ }^{2}$ and Sichugova, L. ${ }^{1}$ \\ ${ }^{1}$ Astronomical Institute of Uzbek Academy of Science, 100052, Astronomicheskaya 33, Tashkent, \\ Uzbekistan, E-mail: dil_faz@yahoo.com,"slola988@gmail.com \\ ${ }^{2}$ State Committee of the Republic of Uzbekistan on Land Resources, Geodesy, Cartography and State \\ Cadaster, 100097, Choponota, 5 Tashkent, Uzbekistan, E-mail: hasan.magdiev@ gmail.com \\ *Corresponding author
}

\begin{abstract}
In this study, the vertical accuracy of the Shuttle Radar Topography Mission Digital Elevation Model Version 2.0 (SRTM30), the Advanced Spaceborne Thermal Emission and Reflection Radiometer Global DEM Version 2.0 (ASTER GDEM2), and Advanced Land Observing Satellite World 3D Digital Surface Model Version 2.1 (ALOS AW3D30) was statistically assessed using GPS data. The Tashkent geodynamical polygon was chosen as a study region, where the land surface can reflect as both natural (tectonic) and man-made (Charvak reservoir load effect) processes. The geometric approach using GPS/leveling stations and EGM96 GGMbased geoid undulations was applied for local geoid modeling. RMSE of $\sim 7.48 \mathrm{~m}, \sim 6.90 \mathrm{~m}$, and $\sim 8.24 \mathrm{~m}$ was obtained for SRTM30, ASTER GDEM2, and ALOS AW3D30, respectively. ASTER GDEM2 proved to be the most accurate DEM with absolute vertical accuracy LE90 of $11.35 \mathrm{~m}$ and $M E$ of $5.25 \mathrm{~m}$ and it is very suitable for geodetic and hydrological studies in this mountainous area.
\end{abstract}

\section{Introduction}

Representing relief by Digital Elevation Model (DEM) is an important task in the understanding of the tectonics, soil genesis, and mapping, land cover, water flow, drainage and floods, slope hazards, soil erosion (Wilson, 2018). Contour lines, topographic maps, Global Positioning System (GPS) measurements, photogrammetry techniques, radar interferometry, stereo satellite images, and airborne laser scanning are the main data sources for DEMs production (Manuel, 2004).

Currently, resolution of the publicly available DEMs based on medium-resolution spatial sensors observations, such as SRTM (Shuttle Radar Topography Mission), ASTER (The Advanced Spaceborne Thermal Emission and Reflection Radiometer), and ALOS (Advanced Land Observing Satellite) improved considerably and offer nearly global coverage in areas with insufficient observational data and difficult to access for observation. But the range of supported applications is still a function of the geographic extent of the coverage area and before using it, users must first be aware of the impact of errors (such as the incomplete density of observations, positional inaccuracy, data entry faults, processing errors, classification, and generalization problems) of the DEM in the area of interest (Wechsler, 2003). Attempts have been made to examine the vertical accuracy of DEM for different territories (Alatawi and Abushandi, 2015, Rabah et al., 2017, Ugur et al., 2018 and Silva et al., 2019).

In Uzbekistan, the only elevation data available is in the form of topographic maps at different scales. (Mirmakhmudov et al., 2019) have developed a local DEM model for four regions (Kashkadarya, Chadak, Surkhandarya, and Ferghana valley) through digitizing 1:500 000 topographic maps, and interpolating elevation values. Today DEM is especially important to assess the role of surface processes in relief production for various man-made objects (geodynamical polygons, nuclear power plants, water reservoirs, etc.) in the country. (Khasanov, 2020) compared vertical accuracy SRTM and ASTER DEMs for the construction of the Kyzylsay and Tashtepa water reservoirs and recommended the use of SRTM DEM for mountainous regions, ASTER DEM for a plane area of the reservoir's construction.

DEMs (such as SRTM and ASTER) are being used as major sources of topographic information for many applications including hydrological analysis and simulations, flood modeling and hazard mapping, geological hazard analysis, and landslide mapping characterization in the country. Despite this the quality and accuracy of the DEMs used and their suitability for these applications was not adequately assessed. The accuracy of a DEM can be assessed by using a comparison with the reference 
point that is measured by using high precision equipment as Global Positioning System (GPS). The goal of this work was to quantify and compare the vertical accuracy of the Shuttle Radar Topography Mission (SRTM30), Advanced Spaceborne Thermal Emission and Reflection Radiometer (ASTER GDEM2), and Advanced Land Observing Satellite (ALOS AW3D30) open access digital elevation models over Tashkent geodynamical polygon (TGP) in Uzbekistan.

\section{Study Area}

Tashkent geodynamical polygon (TGP) has been designed to search earthquake precursors and study local geodynamic phenomena (Yarmukhamedov, 1988). The study area is in the Chirchik river valley from Tashkent city to the Charvak reservoir mainly intended for hydropower generating. Its topography varies from lowlands elevation areas to hilly and mountainous regions (Figure 1). The mountain ranges (Karzhantau, Chatkal, and Kurami), covered by young structures in some areas, surround this field and decrease in the southwest direction. Recent upthrusts and deflections characterize the plain part of the territory. High mountainous regions are located in the south-east and north near the Charvak water reservoir and the maximum heights reach up to $4000 \mathrm{~m}$ above sea level.

\section{Materials and Methods}

\subsection{Digital Elevation Models}

The DEMs evaluated in this study included:

SRTM30 v. 2.0: a near-global digital elevation model (DEM) comprising a combination of data from the Shuttle Radar Topography Mission, flown in February 2000, and the U.S. Geological Survey's GTOPO30 data set. It can be considered to be either an SRTM30 data set enhanced with GTOPO30 or as an upgrade to GTOPO30. 1-arcsecond (about 30 meters) resolution DEM, delivered in $1^{\circ} \times 1^{\circ}$ tiles by the National Aeronautics and Space Administration (NASA) and the National Geospatial-Intelligence Agency (NGA) with the participation of German and Italian space agencies. Systematic interferometric data were collected for each terrain segment at least twice from different angles (on ascending, or north-going and descending orbit pass) to fill in areas shadowed from the radar beam by terrain. The finished product currently is being distributed by NASA/USGS contains 'no-data' termed as voids where water or heavy shadow prevented the quantification of elevation. The vertical accuracy is on average better than $10 \mathrm{~m}$ LE90. Two tiles of the SRTM30 elevation data for the study area were downloaded from https://www.usgs.gov/centers/eros website.

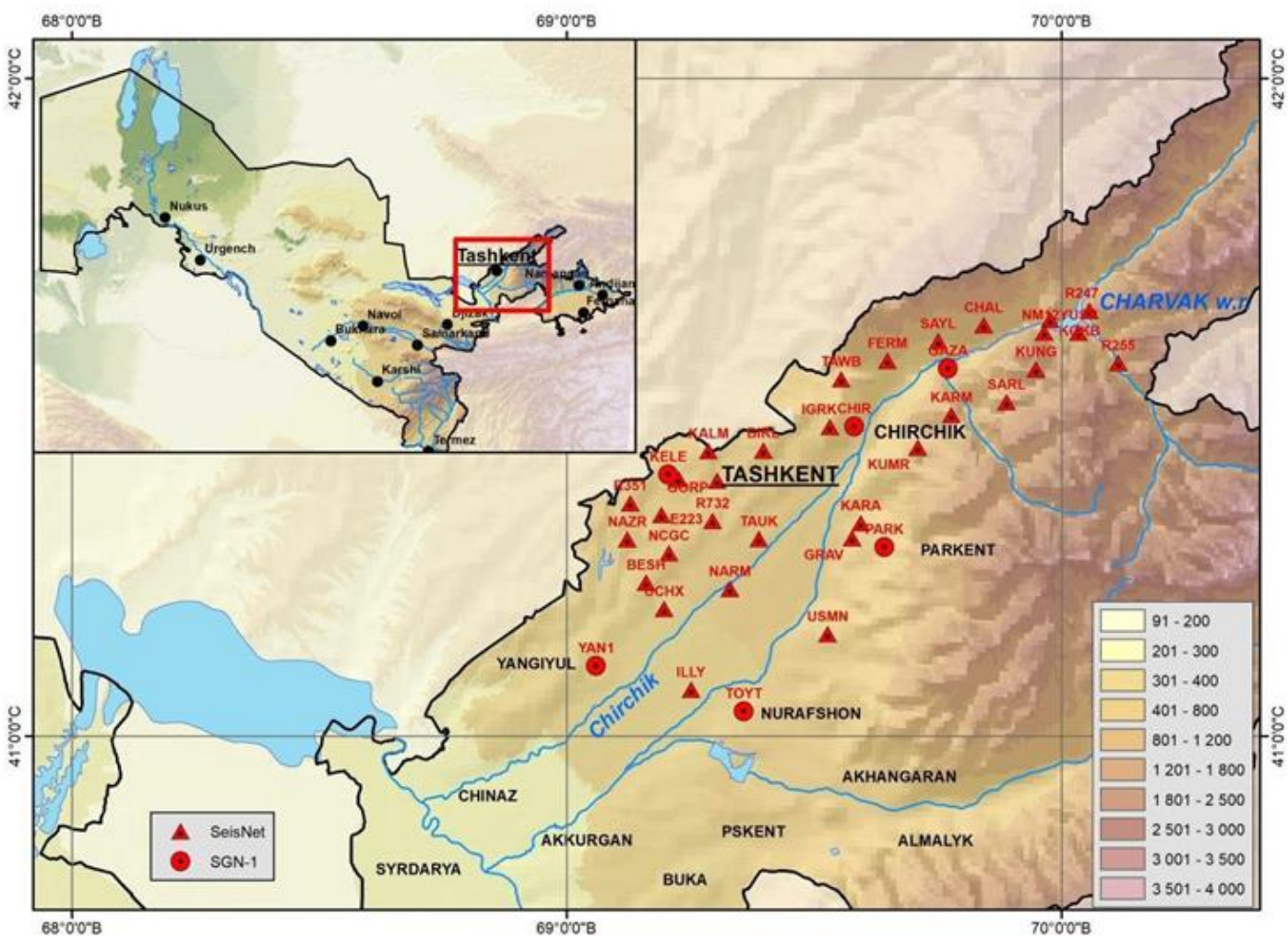

Figure 1: The study area, the 37 GPS stations, and a general overview of the region location from SRTM images 
ASTER GDEM v.2 (ASTER GDEM2): The 1-arcsecond $(30 \mathrm{~m})$ stereoscopic product was generated using 1,880,306 Level-1A scenes acquired between March 1, 2000, and November 30, 2013. ASTER GDEM2 was created by stacking all individual cloud-masked scene DEMs and non-cloud-masked scene DEMs, then applying various algorithms to remove abnormal data. ASTER GDEM2 is distributed in $1^{\circ} \times 1^{\circ}$ tiles. The vertical accuracy is on average better than 15-20 m LE90. The reason for considering this model is ASTER GDEM2 has some advantage over SRTM30 due to its stereo pair has more nadir view when collecting data in very steep and rugged terrain. For this study, 2 tiles of the ASTER GDEM2 elevation data were downloaded from https://asterweb.jpl.nasa.gov/gdem.asp website.

ALOS World 3D (AW3D30): The global digital surface model dataset with a horizontal resolution of approximately 30-meter mesh (1 arcsec. latitude and longitude) generated from $5 \mathrm{~m}$ resolution was released in May 2016 by the Japan Aerospace Exploration Agency (JAXA). The worldwide digital elevation model DEM and ortho-rectified image (ORI) created by utilizing the archived information about the Panchromatic Remote Sensing Instrument for Stereo Mapping (PRISM). PRISM comprised of three panchromatic radiometers that procured along with track stereo images. It had a spatial resolution of $2.5 \mathrm{~m}$ in the nadir-looking radiometer and accomplished worldwide coverage, making it an appropriate potential candidate for exact worldwide DEM and ORI generation. In the last 10 years or so, JAXA has conducted the calibration of the system corrected standard results of PRISM with a specific end goal to enhance absolute accuracies and to validate the high-level products (Tadono et al., 2014). The vertical accuracy is on average better than $7 \mathrm{~m}$ LE90. This is a non-standard version of the ALOS AW3D30 dataset that is provided in a WGS84 ellipsoidal vertical datum. This dataset was converted from the orthometric version using the EGM96 geoid model available. For this study, 2 tiles data were downloaded from https://www.eorc.jaxa.jp/ALOS/en/aw3d30/index.ht $\mathrm{m}$ website.

Further processing of the data took place in ArcGIS v.10.6.1 and Surfer v.16 software.

\subsection{GPS Data}

The data set used for validation of DEMs consists of a total of 37 geodetic points collected during different campaigns in the region. Measurements of the networks were performed using the global positioning system (GPS) and further, we will consider only this system.

SeisNet: Special geodetic network of the Institute of Seismology in the TGP for determination of the velocity and strain field distribution. 31 GPS station measurements, collected during 6 campaigns between 2009 and 2010. The average distance between points equals 5-30 km. Each measurement was made using Ashtech Z-Surveyor receiver with station simultaneously observed during 20-30 days. Site positions and baselines for each epoch were estimated by the Institute of Seismology with Trimble Total Control (TTC) software version 2.73. The free network solution was introduced for each campaign. The GPS data are referenced to the ITRF2014 (Altamimi et al., 2016) and provide geometric (ellipsoidal) heights concerning the WGS84 ellipsoid.

SGN-1: 6 GPS/leveling points from State satellite geodetic network of first class points of the State Committee of the Republic of Uzbekistan on land resources, geodesy, cartography, and state cadaster. SGN-1 data were processed using Gipsy-X software from Jet Propulsion Laboratory and the strategy of the PPP precise point positioning (PPP) has been applied for the analysis (Zumberge et al., 1997). The resulting fiducial-free daily positions were transformed into reference ITRF14 frames using daily seven-parameter transformations supplied by the Jet Propulsion Laboratory and are expected to have horizontal and vertical accuracy of a few centimeters.

The vertical accuracy can be directly estimated by comparing the heights extracted from a DEM and their values interpolated to the location of the GPS points (Gorokhovich and Voustianiouk, 2006, Kiamehr and Sjöberg, 2005 and Khalid et al., 2016). The horizontal datum of SRTM30, ASTER GDEM2, and ALOS AW3D30 is the World Geodetic System 1984 (WGS84). The vertical datum is referred to mean sea level (MSL) as a normal height which is determined by the Earth gravity model (EGM96) as a geoid model (Lemoine et al., 1997). The datum of the GPS's height is the ellipsoidal surface based on the WGS84 reference ellipsoid. GPS data provide the ellipsoidal height and could potentially replace the classical surveying instruments. Ellipsoidal height must be before transformed into normal heights. This technique needs the adopted geoid model and the quality of the geoid model has usually become the limiting factor for such height determination (Sjöberg, 2013). The normal height $(H)$ should be transformed 
into GPS ellipsoidal height (h) using the EGM96 geoid undulations $(N)$ by algebraic summation:

$$
h=H+N
$$

Equation 1

Global geoid height model EGM96, deriving from satellite gravity measurements is free available on the web of the Calculation Service of the International Center of Global Terrestrial Models (ICGEM) (Barthelmes and Köhler, 2016). But the assessment of its accuracy has not been carried out for the territory of Uzbekistan and therefore it may be not sufficient for the user's purposes. Gravimetric measurements are absent for this area either. Many researchers have improved the working efficiency of global Earth gravitational models with the polynomial mathematical model (Peprah et al., 2017), GPS/leveling (Fazilova et al., 2020). The approach utilizes a network of points with known GPS/leveling height anomalies and the EGM96 model. It is based on the interpolation of residual values of height anomalies by applying the interpolation method (Ligas and Kulczycki, 2016).

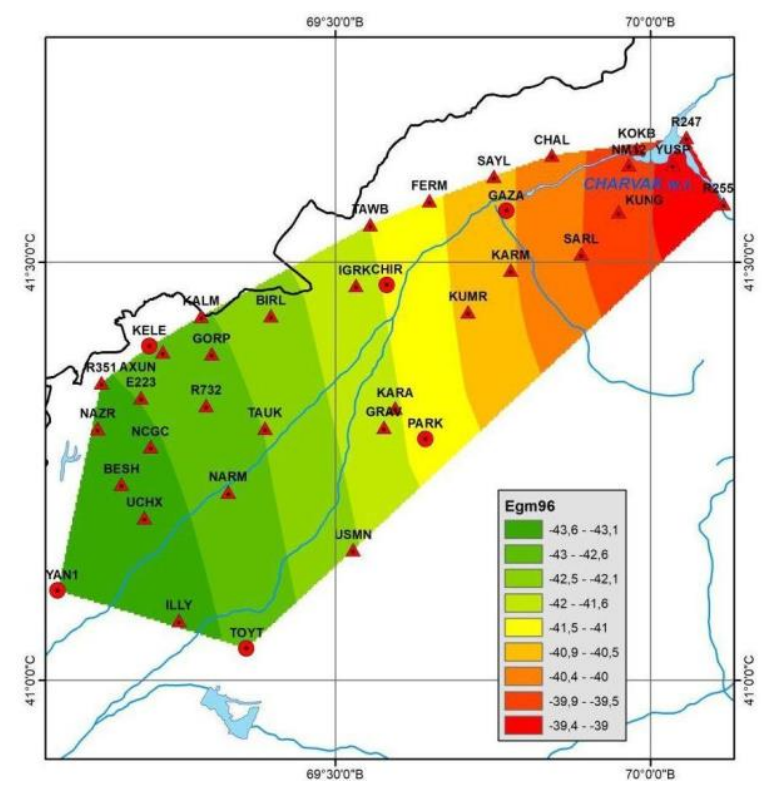

a)
In our case, at each SGN-1 point the difference between the EGM96 geoid undulation $\left(N_{E G M 96}\right)$ and the GPS/leveling value $\left(N_{G P S / L e v e l l i n g}\right)$ is computed:

$$
\Delta N=N_{E G M 96}-N_{G P S / \text { Levelling }}
$$

Equation 2

Using EGM96 1' $\times 1^{\prime}$ global grid of geoid undulations (Figure 2a) a correction surface dataset $1^{\prime} \times 1^{\prime}$ for the study area was built (Figure 2b). A homogeneous surface was created using Natural Neighbor interpolation, one of the most suitable methods in providing accurate approximations of the geoid heights in mountainous areas (Fazilova and Magdiev, 2018). The range of correction values to the geoid undulation is from $-0.86 \mathrm{~m}$ to $2.08 \mathrm{~m}$ with a mean value of $0.84 \mathrm{~m}$ for the region. It should be noted that there are no GPS/leveling stations of the SGN-1 network near the coastal zone of the Charvak reservoir. Therefore, a geoid height correction surface for the coastal zone was created only by the interpolation.

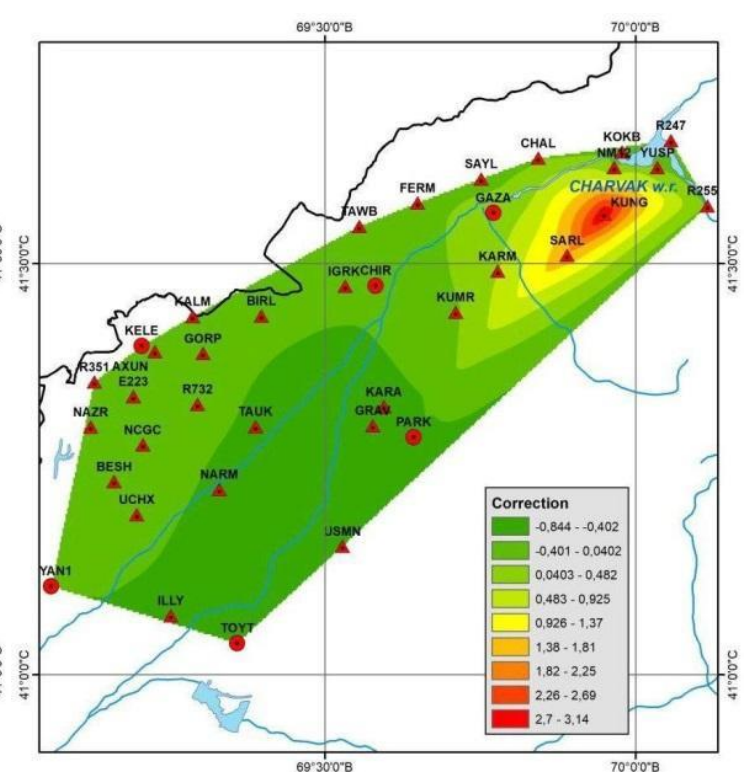

b)

Figure 2: EGM96 geoid undulations (a) and the geoid correction surface (b)

Table 1: Summary statistics of DEMs for the study area

\begin{tabular}{|c|c|c|c|c|c|c|}
\hline & Min, m & Max, m & Mean, m & $\begin{array}{c}\text { RMS, } \\
\mathbf{m}\end{array}$ & $\begin{array}{c}\text { Equation of } \\
\text { correlation GPS and } \\
\text { DEM }\end{array}$ & $\begin{array}{c}\text { Coefficient } \\
\text { of } \\
\text { correlation } \\
\mathbf{R}^{\mathbf{2}}\end{array}$ \\
\hline GPS & 314.07 & 1912.84 & 666.55 & 16.33 & - & - \\
\hline SRTM30 & 304.63 & 1909.45 & 660.52 & 16.35 & $\mathrm{y}=1.0018 \mathrm{x}-7.2123$ & 0.9998 \\
\hline ASTER GDEM2 & 308.54 & 1906.20 & 661.30 & 16.30 & $\mathrm{y}=0.9968 \mathrm{x}-3.1469$ & 0.9998 \\
\hline ALOS AW3D30 & 306.07 & 1903.45 & 660.07 & 16.27 & $\mathrm{y}=0.9956 \mathrm{x}-3.5438$ & 0.9998 \\
\hline
\end{tabular}




\section{Results and Discussion}

After the preprocessing step (local geoid modeling) was completed ellipsoidal height values were derived for each DEM. The general elevation values range between $304 \mathrm{~m}$ to $1909 \mathrm{~m}$ with RMS is about $16.3 \mathrm{~m}$. Statistics of the elevation range, mean value, and standard deviation for SRTM30, ASTER GDEM2, ALOS AW3D30, and reference GPS ellipsoidal heights are presented in Table 1. We also calculated the linear correlation between the GPSmeasured and DEM-derived ellipsoidal height values for each DEM. The correlation coefficient $\mathrm{R}^{2}$ was very high is 0.99 for all cases and did not highlight a significant difference in the three DEM models and reference GPS data. The differences between the DEM ellipsoidal height and the GPS (residuals) resulted in an error value for each point and can be used for a more detailed assessment of the performance of models. The resulting homogeneous surface obtained by the Natural Neighbor method for (GPS - SRTM30), (GPSASTER GDEM2), and (GPS- ALOS AW3D30) residuals are shown in Figure 3 (a-c). The difference in values ranged from $-1.06 \mathrm{~m}$ to $15.2 \mathrm{~m}$, from -3.32 $\mathrm{m}$ to $13 \mathrm{~m}$ from $-2.65 \mathrm{~m}$ to $16.9 \mathrm{~m}$ respectively for SRTM30, ASTER GDEM2, and ALOS AW3D30.

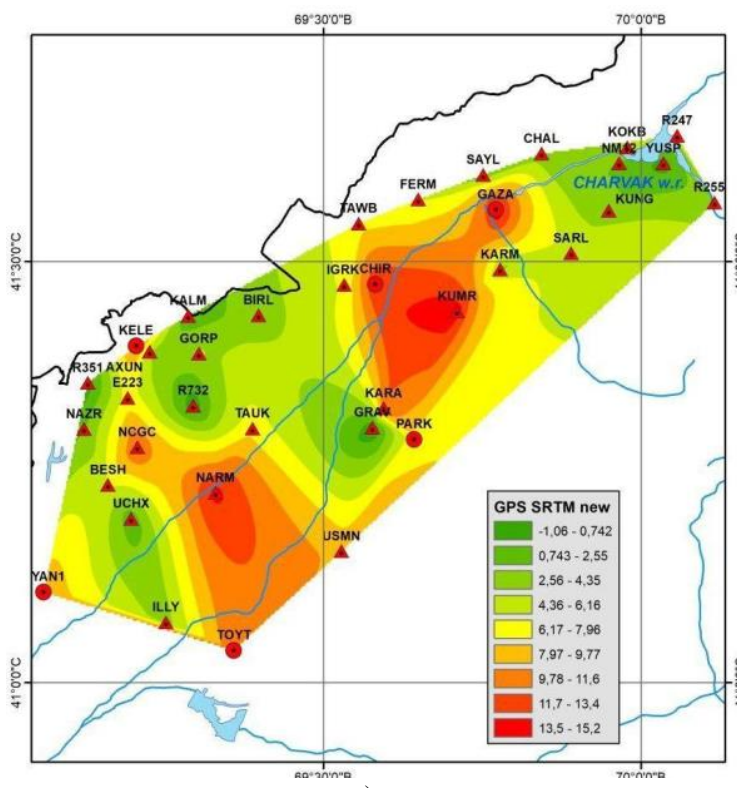

a)

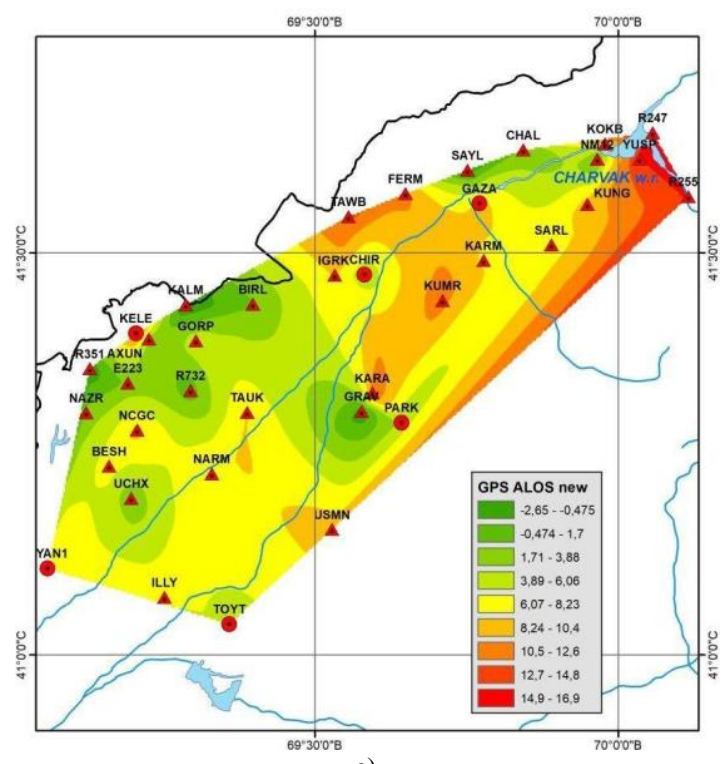

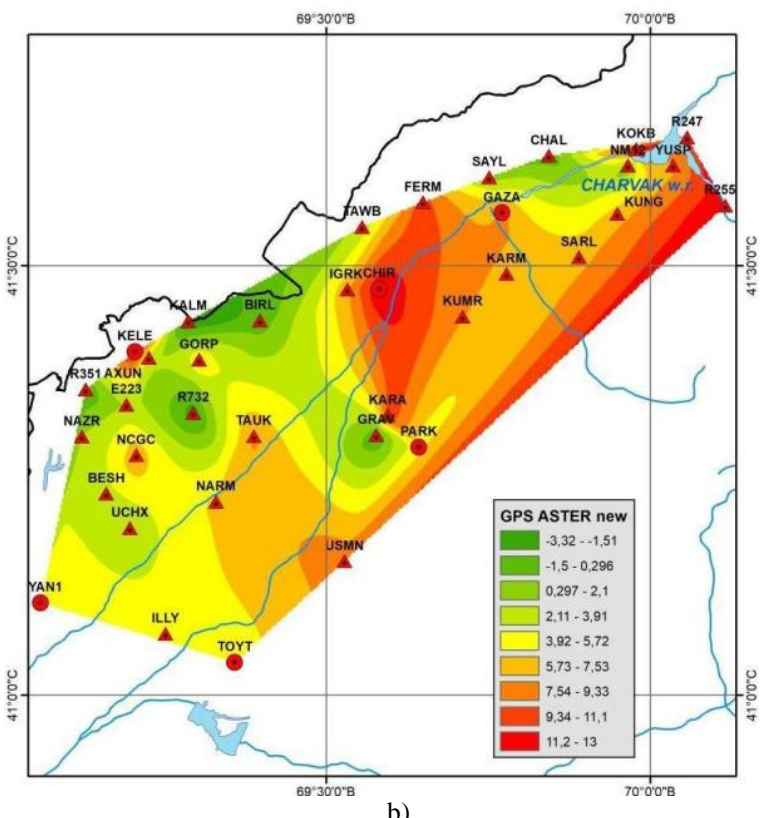

b)

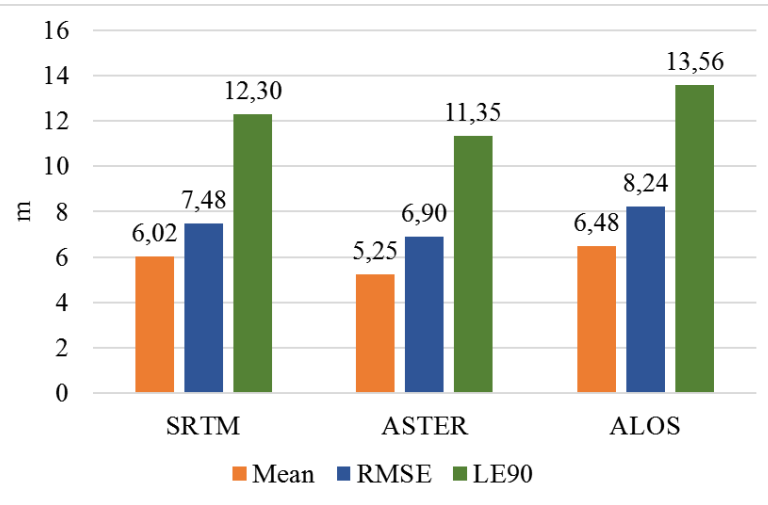

d)

Figure 3: Difference between GPS and DEM-derived ellipsoidal heights distribution: (a) SRTM30, (b) ASTER GDEM2, (c) ALOS AW3D30, and comparative statistics of DEMs (d) 
It should also be noted that residuals for all stations are within $3 \sigma$ (or RMSE). For residuals, the root means square error (RMSE), means error (ME), absolute vertical accuracy at the $90 \%$ confidence level (LE90) were calculated. The first of them, RMSE, characterizes the difference between the modeled values $Z_{M O D E L}$ and the reference ones $\left(Z_{G P S}\right.$ in our case). And second, ME gives an estimate of the offset from the model standard. The absolute vertical accuracy LE90 can be estimated on-base RMSE. The equations as follows (Mukherjee et al., 2013).

$$
\begin{array}{rrr}
R M S E & =\sqrt{\frac{1}{n} \sum_{i=1}^{n}\left(Z_{G P S}-Z_{M O D E L}\right)^{2}} & \\
M E & =\frac{1}{n} \sum_{i=1}^{n}\left(Z_{G P S}-Z_{M O D E L}\right) & \text { Equation } 3
\end{array}
$$

Equation 4

$$
L E 90=R M S E \times 1.6449
$$

Equation 5

Accordingly, the best vertical accuracy of the three DEMs has followed their resolutions. In the case of SRTM30 and ASTER GDEM2 RMSE is comparatively higher than ALOS AW3D30. It is revealed that ASTER GDEM2 produced the lowest RMSE of $6.90 \mathrm{~m}$ with an ME of $5.25 \mathrm{~m}$ (Figure 3d). It has been found that SRTM30 and ASTER GDEM2 models' elevation data featured a much greater absolute vertical accuracy of $12.30 \mathrm{~m}$ and $6.90 \mathrm{~m}$ respectively. ASTER GDEM2 statistical parameter variation is very high as compared to other DEM. Although the offset parameter (ME) for SRTM30 and ASTER GDEM2 models is almost the same, the ASTER GDEM2 gives a closer estimate of the relief of the region according to the absolute vertical accuracy estimation (LE90=11.35 m). It can be announced that the ASTER GDEM2 is the optimal DEM for the study area. While all the three DEMs overestimated the true ground elevations, the mean and standard deviations of the differences in elevations were found to be lower in ALOS AW3D30 compared to SRTM30 and ASTER GDEM2. At this step of the accuracy assessment, we can make a preliminary conclusion that SRTM30 and ASTER GDEM2 models can be used for practical purposes in the region.

To estimate local geoid model analysis of calculated residuals has been carried out separately for different parts of the TGP. The region under study was conditionally divided into four main groups. The first one belongs to the Charvak coastal zone (KOKB, NM12, YUSP, CHAL, KUNG, R247, R255, SAYL, FERM). The second and the third are separated from each other by the Chirchik river and hereinafter called conditionally the Northern zone (IGRK, KALM, NAZR, NCGC, R351, R732, TAUK, TAWB, UCHX) and the Southern zone (ILLY, GRAV, KARA, KARM, KUNG, KUMR, NARM, SARL, USMN). And finally, the last station group is presented by 6 GPS/leveling points (CHIR, GAZA, KELE, TOYT, PARK, YAN1) of the SGN-1 network. The differences between the DEM ellipsoidal height and the GPS (residuals) for each point are shown in Figure 4.

a) Northern part, b) Southern part, c) coastal zone of the Charvak reservoir and d) GPS/leveling point The maximum residual values equal to $13.01 \mathrm{~m}$ and $17.01 \mathrm{~m}$ for the ASTER GDEM2 and ALOS AW3D30, respectively, were obtained for the coastal zone (Figure 4c). This is clearly seen for the stations R247, R255, YUSP located on the eastern part of the reservoir. As was noted before, the area of the Charvak water reservoir does not have GPS/leveling stations. Therefore, a geoid was modeled for this part of the area by the interpolation. Undoubtedly, good agreement between the DEMs was obtained for the group of GPS/levelling stations.

\section{Conclusions}

The present study was carried out for the evaluation of the vertical accuracy of three DEMs (SRTM30, ASTER GDEM2, and ALOS AW3D30) for the Tashkent geodynamical polygon in Uzbekistan. The GPS network of TGP was used as reference data. The initial accuracy assessment was based on the determination of differences between the DEMs converted to points and the reference GPS data. EGM96 geoid was refined using GPS/leveling points of state SGN-1 network. DEMs elevation values were transferred from normal height to ellipsoidal height based on the adjusted EGM96 geoid undulations. In this regard, it should be noted that the SGN-1 network is mainly located in the central part of the study area and does not have data in the Charvak reservoir area. The maximum residual values were obtained for this area of TGP. Therefore, for the coastal part of the Charvak water reservoir, the obtained corrected surface of the geoid undulations should be refined in future works. In general, the results showed that open source DEMs are very suitable for performing geodetic and hydrological studies in the Tashkent geodynamical polygon. While all the three DEMs overestimated the true ground elevations, the mean and standard deviations of the differences in elevations were found to be lower in ALOS AW3D30 compared to SRTM30 and ASTER GDEM2. 


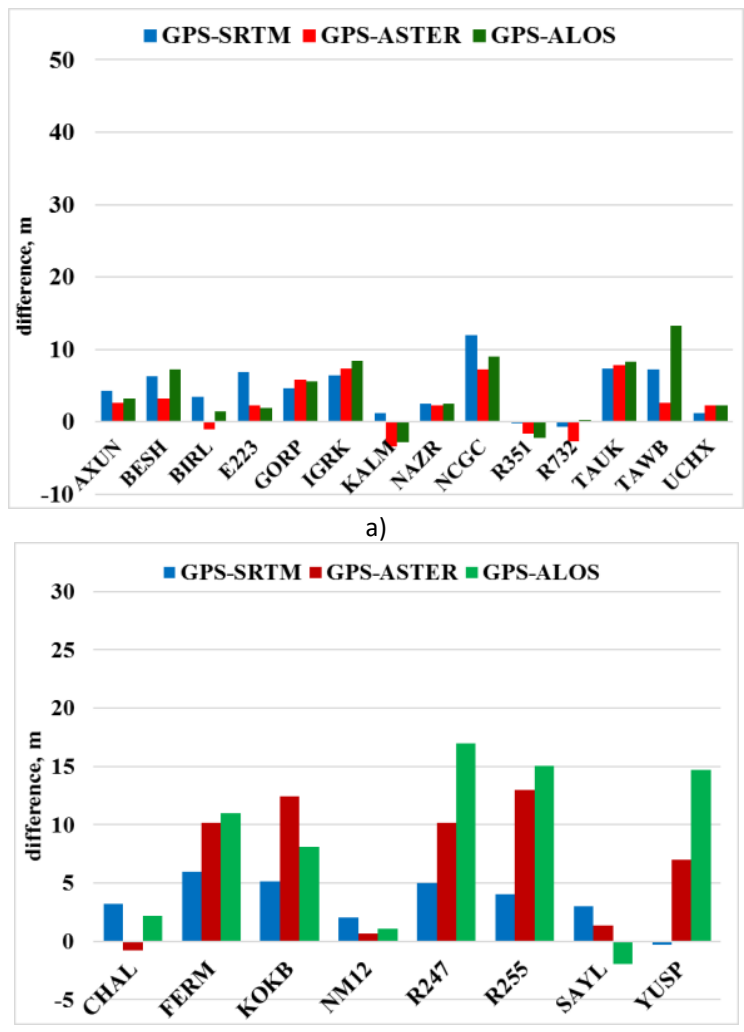

c)

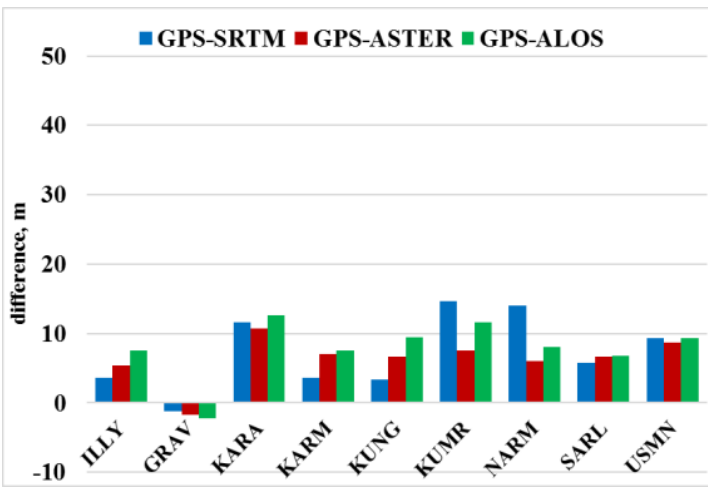

b)

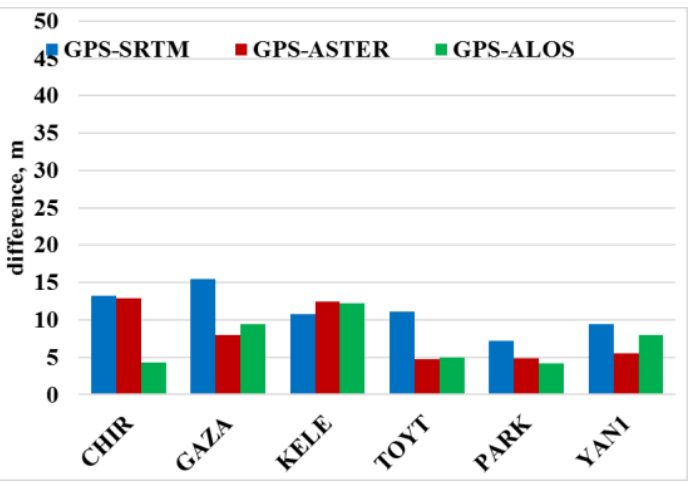

d)

Figure 4: The differences obtained in the ellipsoidal heights between each of the DEMs and the 37 GPS points for different areas: a) Northern part, b) Southern part, c) coastal zone of the Charvak reservoir and d) GPS/leveling point

We found the accuracy of ASTER GDEM2 is better than SRTM30 and ALOS AW3D30. It had produced the lowest RMSE of $6.90 \mathrm{~m}$ with an ME of $5.25 \mathrm{~m}$. This is due to ASTER GDEM2 has some advantage over SRTM30 due to its stereo pair has more nadir view when collecting data in very steep and rugged terrain like our study area.

\section{Acknowledgement}

This work was carried out within the scientific and applied project FA-A5-F014 of the Astronomical Institute of Uzbekistan with the financial support of the Ministry of Innovative Development of the Republic of Uzbekistan. We are very grateful to the Institute of Seismology and the National Center of Geodesy and Cartography, who organized GPS experiments and made the data available to this study. GPS data were processed using the GIPSY OASIS II software and data products from the Jet Propulsion Laboratory.

\section{References}

Alatawi, S. and Abushandi, E., 2015, Evaluation of ASTER Satellite Imagery in Comparison with
Topographic Map and GPS Datasets for Tracking Tabuk City Digital Elevation Model. $J$. of Earth Science \& Climatic Change, Vol. 6(2), doi:10.4172/2157-7617.100025.

Altamimi, Z., Rebischung, P., Métivier, L. and Collilieux, X., 2016, ITRF2014: A New Release of the International Terrestrial Reference Frame Modeling Nonlinear Station Motions. Journal of Geophysical Research: Solid Earth, Vol. 121(8), 6109-31. https://doi.org/10.1002/2016jb013098.

Barthelmes, F. and Köhler, W., 2016, International Centre for Global Earth Models (ICGEM), in: Drewes, H., Kuglitsch, F., Adám, J. et.al., The Geodesists Handbook, Journal of Geodesy, Vol. 90, No.10, 907-1205, https://doi.org/10.5194/egusphere-egu2020-3511.

Fazilova, D. and Magdiev, H., 2018, Comparative Study of Interpolation Methods in Development of Local Geoid. International Journal of Geoinformatics, Vol.14(1), 29-33.

Fazilova, D., Magdiev, H. and Halimov B., 2020, High-precision satellite leveling and investigation of the local geoid model in the territory of Kashkadarya region. EPRA International Journal of Economic Growth and 
Environmental Issues, Vol. 8(4), 31-35, https://doi.org/10.36713/EPRA5788

Gorokhovich, Y. and Voustianiouk, A., 2006, Accuracy Assessment of the Processed SRTMBased Elevation Data by CGIAR Using Field Data from USA and Thailand and Its Relation to the Terrain Characteristics, Remote Sensing of Environment, Vol. 104, No. 4, 409-15. doi.org/10.1016/j.rse.2006.05.012.

Khalid, N. F., Din, A. H. M., Omar, K. M., Khanan, M. F. A., Omar, A. H., Hamid, A. I. A. and Pa'Suya, M. F., 2016, Open-source Digital Elevation Model (DEMs) Evaluation with GPS and Lidar Data. ISPRS - International Archives of the Photogrammetry, Remote Sensing and Spatial Information Sciences XLII-4/W1, 299306, https://doi.org/10.5194/isprs-archives-xlii4-w1-299-2016.

Khasanov, Kh., 2020, Evaluation of ASTER DEM and SRTM DEM Data for Determining Tthe Area and Volume of the Water Reservoir. IOP Conf. Series: Materials Science and Engineering, 883, 012063IOP Publishing doi:10.1088/1757-899X/883/1/012063.

Kiamehr, R. and Sjöberg, L. E., 2005, Effect of the SRTM Global DEM on the Determination of a High-Resolution Geoid Model: A Case Study in Iran. Journal of Geodesy, Vol. 79(9), 540-51, https://doi.org/10.1007/s00190-005-0006-8.

Lemoine, F. G., SmithL, D. E., Kunz, L., Smith, R., Pavlis, E. C., Pavlis, N. K., Klosko, S. M., Chinn, D. S., Torrence, M. H., Williamson, R. G., , C. M., Rachlin, E., Wang, Y. M., Kenyon, S. C., Salman, R., Trimmer,, R., Rapp, R. H. and Nerem, R. S., 1997, The Development of the NASA GSFC and NIMA Joint Geopotential Model. International Association of Geodesy Symposia Gravity, Geoid and Marine Geodesy, Vol. 117, 461-69. https://doi.org/10.1007/978-3662-03482-8_62.

Ligas, M. and Kulczycki, M., 2016, Kriging and Moving Window Kriging on a Sphere in Geometric (GNSS/levelling) Geoid Modelling. Survey Review, Vol. 50(359), 155-162. doi:10.1080/00396265.2016.1247131.

Manuel, P., 2004, Influence of DEM Interpolation Methods in Drainage Analysis. GIS Hydro 04, Texas, USA.

Mirmakhmudov, E., Gulyamova, L. and Juliev, M., 2019, Digital Elevation Models Based on the Topographic Maps. Coordinates. 31-36.

Mukherjee, S., Joshi, P., Mukherjee, S., Ghosh, A., Garg, R. and Mukhopadhyay, A., 2013, Evaluation of Vertical Accuracy of Open Source Digital Elevation Model (DEM), International Journal of Applied Earth Observation and
Geoinformation, Vol. 21, 205-217, doi: 10.1016/j.jag.2012.09.004.

Peprah, M. S., Ziggah, Y. Y. and Yakubu, I., 2017, Performance Evaluation of the Earth Gravitational Model 2008 (EGM2008) - A Case Study. South African Journal of Geomatics, Vol. 6(1), 47-72. https://doi.org/10.4314/sajg.v6i1.4.

Rabah, M., El-Hattab, A. and Abdallah, M., 2017, Assessment of the Most Recent Satellite Based Digital Elevation Models of Egypt. NRIAG Journal of Astronomy and Geophysics, Vol. 6(2), 326-335, doi.org/10.1016/j.nrjag.2017. 10.006 .

Silva, L. F., Penha, A. and Carvalho, J. A., 2019, Comparison Between Absolute and Relative Positional Accuracy Assessment - A Case Study Applied To Digital Elevation Models. Boletim De Ciências Geodésicas, Vol. 25 (1), https://doi.org/10.1590/s1982217020190001000 03.

Sjöberg, L. E., 2013, The Geoid or Quasigeoid Which Reference Surface Should be Preferred for a National height system?. Journal of Geodetic Science, Vol. 3(2), 103-109.

Tadono, T., Ishida, H., Oda, F., Naito, S., Minakawa, K. and Iwamoto, H., 2014, Precise Global DEM Generation by ALOS PRISM. ISPRS Annals of the Photogrammetry, Remote Sensing and Spatial Information Sciences, Vol. II-4, 71-76.

Wilson, J. P., 2018, Environmental Applications of Digital Terrain Modeling, Wiley Blackwell.

Wechsler, S. P., 2003, Perceptions of Digital Elevation Model Uncertainty by DEM Users. URISA Journal, Vol. 15, 57-64.

Yarmukhamedov, A. R., 1988, The Morphostructure of the Median Tien Shan and its Relationship with Seismicity, Tashkent: Fan, 163 (In Russian), https://www.geofund.am/files/library/1/15247392644395.pdf.

Ugur, A., Besol, B. and Sertel, E., 2018, Accuracy Assessment of Different Digital Surface Models. ISPRS International Journal of GeoInformation, Vol. 7(3), 114, https://doi.org/10.3390 /ijgi7030114.

Zumberge, J. F., Heflin, M. B., Jefferson, D. C., Watkins, M. M. and Webb, F. H., 1997, Precise Point Positioning for the Efficient and Robust Analysis of GPS Data from Large Networks. Journal of Geophysical Research: Solid Earth, Vol. 102, No. B3, 5005-5017, https://doi.org/10.1029 /96jb0386. 